\title{
A self-evaluation tool of sustainability concepts in higher education institutions courses
}

\section{Elisabetta Venezia ${ }^{1}$, Fabio Pizzutilo ${ }^{2}$}

${ }^{1}$ Department of Economics and Finance, University of Bari Aldo Moro, Italy, ${ }^{2}$ Department of Economics, Management and Business Law, University of Bari Aldo Moro, Italy.

\begin{abstract}
In this paper, a self-evaluation tool is developed to allow educators and Higher Education Institutions to assess their efforts in pursuing Education for Sustainable Development. The composite index (which create a representation of a sector performance) here proposed allows the individual components that contribute to the pursuit of sustainability in education to be grasped in isolation and, at the same time, provides an overall evaluation measure of all the elements taken into consideration. The index is based on the identification of elements that measure the efficiency of the allocated expenditure. At the same time, it encompasses measures of the impact and perception of sustainability concept by staff and students. Albeit in a laborious way, the application of the tool leads to an assessment of education for sustainable development results. This composite indicator can be used in a replicative manner elsewhere and offers the advantage of being able to carry out comparative evaluative analyses. This is due to its adaptive flexibility.
\end{abstract}

Keywords: Sustainability; higher education institutions; evaluation; measure; criteria; education for sustainable development. 


\section{Introduction}

The growing sensitivity towards the issues of well-being, sustainability and social responsibility stimulates the production of statistics and analyses useful for evaluating their features and trends. Nevertheless, none structured and shared systems of evaluation has been developed so far by scientific literature. At the level of statistical data collection, experimental projects have been launched to collect information directly from the subjects involved and produce some indicators on the diffusion of the orientation towards sustainability in education and training (Boer, 2013; Alghamdi et al., 2017; Boeve-de Pauw $\&$ Van Petegem, 2018). The goal of these instruments is to increase the information available to users and evaluators, exploiting the existing information and designing new information sources based on adequate experimentation (Patterson et al., 2020). Nevertheless, a tool that enables the qualitative and quantitative classification and analysis of Higher Education Institutions' (HEIs) CSR-/sustainability related courses is still lacking. We believe that it is essential to raise the next generation into eco-conscious, self-sufficient world citizens who understand the immediacy of environmental responsibility. We filled this gap by developing a self-evaluation tool that provides an overall assessment of higher education courses and takes into account both course and institution level criteria. The tool can be employed by any HEI, as well as by Universities, already integrating or interested in integrating sustainability and/or CSR issues into teaching. The self-evaluation tool could also be of special interest for institutions promoting responsible management education. Anyway, the tool proposed here will be further developed to supply different solutions according to the type of institutions and aspects that need to be investigated. Concrete applications will be presented in the near future.

In the first part of this article, we briefly propose a literature framework related to the sustainable measurement and consideration in evaluation exercise. Then, a composite index is presented as a novel contribution in the self-evaluation context of higher education institutions. Concluding remarks are included in the final part of this paper.

\section{Literature framework}

Although relevant differences in approaches, the current literature on sustainability applied to learning and education, considered as a measure or an indicator of social, economic, and environmental paradigm, is growing in terms of original contributions. Qualitative and quantitative approaches have been followed so far. The most relevant of them are briefly reviewed afterward. 


\subsection{Qualitative approaches}

Filho et al., 2018, Kankovskaya, 2016, and Ojala, 2017 point out that in order to include sustainable teaching concepts in HEIs policies, existential, emotional, cognitive, and action components need to be taken into account. Furthermore, it is important to assume that a more holistic integration of sustainable development principles in the different university functions leads to a higher awareness of the role played by different university actors, fostering cultural and transformational shifts to their learning frameworks and visions related to sustainable development (Katsoulakos \& Yannis Katsoulacos, 2007; Singer-Brodowski et al., 2019). Since a large variation in perceptions of sustainability is to be expected, flexibility, continuous training and routines provides essential opportunities for integration (Sammalisto et al., 2015). Niedlich et al., 2019 remarked the importance of soft elements like organisational culture, responsibility for sustainable development and behavioral change. Ultimately, the need to formulate principles for the national innovation system based on the concept of sustainability is underlined in several studies (Waples et al., 2008; Kemper et al., 2019 , to cite only a few).

\subsection{Quantitative approaches}

Bask et al. (2020), Vargas, V.R. et al. (2019), de Gaulmynn \& Dupre (2019), propose an innovative quantitative evaluation of the sustainable performance of student projects throughout their design processes. They suggest how to change organizational processes by integrating sustainable development in different areas of education. The analytical techniques they proposed were coding, stakeholder centrality, and network density measures focused at highlighting areas for policy development and implementation. Two instruments proposed to measure value priorities are surveys and questionnaires. Their results suggested that the existing networks identified in the policy frameworks may not support the effective integration of sustainable development in higher education. Low-density of the national networks, the lack of a clear governance vocabulary for national policy frameworks, and the lack of explicit funding flows between organizations pose problems for institutional change towards sustainable development in higher education.

The evaluation tools used elsewhere show a systematic separation of the single elements to be assessed. In these papers the authors do not elaborate a composite indicator that allows an overall assessment of the sustainability within the courses attended and provided. It is precisely this missing element that motivated us to propose an overall indicator useful for self-evaluation analyses. 


\section{Definition of a composite indicator}

The issue of aggregating the different criteria (dimensions) in an indicator or composite criterion originates from the consideration that although a political choice is ultimately reduced to a decision about whether or not to take an action, and about the intensity of the measure, the decision may have a multiplicity of objectives. As a consequence, the evaluation (ex-ante and ex-post) of the corresponding public interventions will be guided by a multiplicity of indicators, capable of capturing, with a certain approximation, to what extent the implemented policies, among which sustainability is included, are able to achieve results satisfactorily in terms of each goal (Pacheco et al., 2009).

Since the multiplicity of objectives must lead to a one-dimensional choice (provision or not of the service and its intensity), it is required that the multiplicity of objectives that can be reached by the choice are aggregated into a single indicator, capable of summarizing, in a manner consistent with administrations' priorities, the effects of the choice on all relevant dimensions. A composite index can be used for this purpose. A composite indicator makes it possible to guide the choices of the administration in a manner consistent with the priorities of the institution and to effectively communicate an understandable and objective choice criterion to the stakeholders and to the public. At the same time, attention must be paid to the problems that may arise if political and administrative choices are made by relying uncritically on a composite indicator (Asif \& Searcy, 2014; Asif \& Raouf, 2013; Asif \& Searcy, 2013).

The main critical issues to be aware of, when a choice is guided by a composite indicator are the following (for a comprehensive overview see D'Inverno \& De Witte, 2020; El Gibaria et al., 2018):

a. A composite indicator must be constructed transparently, highlighting the mechanisms that determine the final value of the indicator. Otherwise, it will be difficult to convince external parties of the validity and impartiality of the criterion used. Furthermore, the identification of possible remedies to critical situations could be complex in the absence of an unambiguous interpretative key.

b. There are wide margins of discretion in the choice of components, in the relative weight to be given to each of them, and about the assumptions regarding the level of complementarity of the various dimensions. These choices must be made explicit together with the illustration of the results obtained.

c. Including among the dimensions some phenomena that are difficult to directly observe and measure can be challenging and may lead to biased results.

Keeping these critical issues in mind, in this paper three categories of indicators have been identified: 
1. Quantitative data. Indicators that represent a proxy of efficiency: i) cost of the single course/number of the enrolled students; ii) variation in the number of the enrolled students, a factor that may also reflect preference choices.

2. Strategic objectives of the higher education institutions. Indicators representing the relevant dimensions of sustainability interventions in university/course policy. For each course, a judgment of relevance is formulated with respect to the achievement of the same objectives. It derives from the judgment of higher education institution representatives for educational programs and of in-house committee. Twelve criteria, grouped into three dimensions are here integrated:

a. people: identification, consultation, involvement, co-creation

b. culture: the evaluation here regards the governance, the strategy related to sustainable policies, the inclusive context and the measurement of the results

c. mission: curricula, research, outreach, funding.

3. Impact on students. Indicator resulting from judgments given by students with respect to the impact generated by participation in courses on a series of variables (for example, expansion of knowledge, possible improvement of employability etc.).

The same weight, $\mathrm{w}_{\mathrm{j}}=1 / \mathrm{N}$, is assigned to each indicator, and the following formula is used to normalize the values of the individual indicators:

$$
\text { normalization }=\frac{x-\min \left\{x_{i}\right\}}{\max \left\{x_{i}\right\}-\min \left\{x_{i}\right\}}
$$

However, different weights can be assigned if some aspects are considered to be more relevant than others. In Eq. (1) a neutral position is maintained.

With reference to the composite indicator, this is the result of the combination of a plurality of aspects both of an objective type, linked to the costs incurred for the realization of the courses and to the variation of enrollments, and of a perceptive type, linked to what is perceived by the HEI and by students. The ability to break down the indicator and consider the individual components, supports the institution in its choices in preferring some aspects to others. Henceforth, the decision-making process can be modeled according to the objectives and needs that the actuator wants to consider from time to time. 
Table 1. Construction of a composite index.

\begin{tabular}{|c|c|c|c|c|c|c|}
\hline \multirow[t]{2}{*}{ Course } & \multicolumn{2}{|c|}{$\begin{array}{l}\text { Quantitative data } \\
\text { (A) }\end{array}$} & \multicolumn{2}{|c|}{$\begin{array}{c}\text { Strategic objectives } \\
\text { (B) } \\
\end{array}$} & \multirow{2}{*}{$\begin{array}{c}\begin{array}{c}\text { Impact on } \\
\text { students } \\
\text { (C) }\end{array} \\
\begin{array}{c}\text { Students' } \\
\text { index }\end{array}\end{array}$} & \multirow{2}{*}{$\begin{array}{c}\text { Total } \\
(\mathrm{A})+(\mathrm{B})+ \\
(\mathrm{C})=(\mathrm{D}) \\
\text { Composit } \\
\text { e index }\end{array}$} \\
\hline & $\begin{array}{c}\text { Efficiency } \\
\text { (cost/no. of } \\
\text { enrolled } \\
\text { students) }\end{array}$ & $\begin{array}{l}\text { Variation in } \\
\text { the no. of } \\
\text { enrolled } \\
\text { students }\end{array}$ & $\begin{array}{c}\text { In-house } \\
\text { committee }\end{array}$ & $\begin{array}{c}\text { Responsible } \\
\text { officers for } \\
\text { educational } \\
\text { programmes }\end{array}$ & & \\
\hline$X$ & $0 \ldots$ & $0 \ldots$ & & $0 .$. & $0 \ldots$ & $\ldots$ \\
\hline Y & 0... & 0... & & 0... & $0 \ldots$ & $\ldots$. \\
\hline
\end{tabular}

The component (A) is the parameter measuring efficiency related to the service costs and the number of students enrolled in each course. Variation in the number of students enrolled is an additional information which can be considered as another important tool of benchmarking performance based on historical performance. The component (B) is representative of strategic objectives which are considered reachable by the institution through the supplied courses. To successfully consider all the different aspects it is important to follow a comprehensive (whole institution) approach that takes the impacts of all core elements into account. Therefore, we propose to consider two groups of people who have a full knowledge of strategic objectives linked to the sustainability. Firstly, an in-house committee measuring Education for Sustainable Development (ESD) has to be selected. The ease of achieving the strategic objectives linked to sustainability will be verified through graduated responses with a scale from 0 to 100 . Secondly, HEI representatives for educational programs express their evaluation through the same approach.

Component (C) completes the assessment by segments thanks to the contribution of the students involved in the courses in which sustainability is taught. The elements on which to express an opinion on the impact are:

- change of knowledge oriented towards sustainability

- effectiveness of the courses with reference to the new needs of the labor market

- correspondence between expectations and results achieved.

In addition, in this case an increasing scale from 0 to 100 is used to express the evaluation.

The individual components can be read and analyzed individually. However, a full appreciation of the inclusion of sustainability in courses by higher education institutions is given by the overall weighting of all components. 


\section{Concluding remarks}

In this paper, we deal with the problem of the construction of a multidimensional composite indicator for a self-evaluation exercise. In our proposal, along with indicators measuring the efficiency of HEIs, a group of indicators that assesses the internal and the social dimensions of the educational system in terms of sustainability in taken into account. Flexibilities in the actual composition of the indicator assure consistency with evaluation aims and needs, and adherence with HEI's ESD policy. At the same time, arbitrariness in the choice of the components and in their weight induce possible bias in the assessment. Therefore, sound assumptions need to be validated in order to derive an unbiased composite indicator. Finally, a wider participation of relevant internal and external stakeholders in the process and a thorough transparency of the dimensions, the variables, the measures, the weights and the methods foster a larger recognition of the assessment results and further ideas and actions to improve ESD policies.

The methodology presented here will be further developed both with reference to university institutions and through the concrete application to some realities.

\section{Acknowledgements}

The study is part of EFFORT (EFFectiveness Of Responsible Teaching), a project (partially) funded by the Erasmus+ grant program of the European Union under grant no. 2019-1-DE01KA203-005057. Neither the European Commission nor the project's national funding agency $\mathrm{DAAD}$ are responsible for the content or liable for any losses or damage resulting of the use of these resources. We are grateful to the members of EFFORT team for their precious suggestions and insights while developing the paper.

\section{References}

Alghamdi, N., den Heijer, A., \& de Jonge, H. (2017). Assessment tools' indicators for sustainability in universities: an analytical overview. International Journal of Sustainability in Higher Education, 18(1), 84-115. https://doi.org/10.1108/IJSHE-042015-0071.

Asif, M., Raouf, A. (2013). Setting the course for quality assurance in higher education. Quality \& Quantity, Vol. 47 No. 4, pp. 2009-2024.

Asif, M., Searcy, C. (2013), "Determining the key capabilities required for performance excellence in higher education", Total Quality Management \& Business Excellence, Vol. 25, No. 1, pp. 22-35.

Asif, M., Searcy, C. (2014), A composite index for measuring performance in higher education institutions. International Journal of Quality \& Reliability Management, 31(9):983-1001. 
Bask, A., Halme, M., Kallio, M., \& Kuula, M. (2020). Business students' value priorities and attitudes towards sustainable development. Journal of Cleaner Production, 264, 121711.

Boer, P. (2013). Assessing Sustainability and Social Responsibility in Higher Education Assessment Frameworks Explained, in Caeiro, S., Leal Filho, W., Jabbour, C., Azeiteiro, U. M., (Eds.). Sustainability Assessment Tools in Higher Education Institutions, Springer International Publishing Switzerland.

Boeve-de Pauw J., Van Petegem, P. (2018). Eco-school evaluation beyond labels: the impact of environmental policy, didactics and nature at school on student outcomes. Environmental Education Research, 24(9), 1250-1267, DOI:10.1080/13504622.2017.1307327.

D'Inverno, G.-De Witte, K. (2020). Service level provision in municipalities: A flexible directional distance composite indicator. European Journal of Operational Research, 286(3), 1129-1141.

El Gibari, S.- Gómez, T. \& Ruiz, F. (2018). Evaluating university performance using reference point based composite indicators. Journal of Informetrics, 12(4), 1235-1250.

de Gaulmynn, C.-Dupre, K. (2019). Teaching sustainable design in architecture education: Critical review of Easy Approach for Sustainable and Environmental Design (EASED). Frontiers of Architectural Research. 8(2), 238-260.

Filho, W.L., Raath, S., Lazzarini, B., Vargas, V.R., de Souza, L., Anholon, R., Quelhas, O.L.G., Haddad, R., Klavins, M., \& Orlovic, V.L. (2018). The role of transformation in learning and education for sustainability. Journal of Cleaner Production, 199, 286-295.

Kankovskaya, A.R. (2016). Higher Education for Sustainable Development: Challenges in Russia. Procedia CIRP, 48, 449 - 453.

Katsoulakos, T.- Katsoulacos, Y. (2007). Integrating corporate responsibility principles and stakeholder approaches into mainstream strategy: a stakeholder-oriented and integrative strategic management framework. Corporate Governance, 7(4), 355-369.

Kemper, J. A., Ballantine, P. W., \& Hall, C. M. (2019). Combining the 'why' and 'how' of teaching sustainability: the case of the business school academics. Environmental Education Research, 25(12), 1751-1774, DOI: 10.1080/13504622.2019.1667959

Niedlich, S., Kummer, B., Bauer, M., Rieckmann, M., \& Bormann, I. (2019). Cultures of sustainability governance in higher education institutions: A multi-case study of dimensions and implications. Higher Education Quarterly, pp. 1- 18. https://doi.org/10.1111/hequ.12237.

Ojala, M. (2017), Hope and anticipation in education for a sustainable future, 94, 76-84.

Pacheco, E.R.- Fernández-Ramírez, B., \& Andrés, P.C. (2009). Quality Criteria for SelfEvaluation in Higher Education. Journal of MultiDisciplinary Evaluation, 6(11), ISSN 1556-8180.

Patterson, M. S., Prochnow, T., Richardson, R. G., \& Jackson, K. P. (2020). Using network analysis to conduct a system-wide program evaluation within a university. Evaluation and Program Planning, 79, 101783.

Sammalisto, K., Sundström, A., \& Holm, T. (2015). Implementation of sustainability in universities as perceived by faculty and staff - a model from a Swedish university. 
Journal of Cleaner Production, 45-54, https://doi.org/10.1016/j.jclepro.2014.10.015.

Singer-Brodowski, M., Etzkorn, N., \& von Seggern, J. (2019). One transformation path does not fit all - Insights into the diffusion processes of education for sustainable development in different educational areas in Germany. Sustainability, 11(1), 269. https://www.mdpi.com/2071-1050/11/1/269.

Vargas, V.R.-Lawthom, R.- Prowse,A.-Randles, S. \& Tzoulas, K. (2019). Sustainable development stakeholder networks for organisational change in higher education institutions: A case study from the UK. Journal of Cleaner Production, 208,470-478. 